\title{
Development of a fully debonded cone bolt for rockburst support
}

\author{
M. Cai Laurentian University, Canada \\ D. Champaigne Mansour Mining Inc., Canada
}

P.K. Kaiser Centre for Excellence in Mining Innovation, Canada

\begin{abstract}
The development of cone bolts is briefly reviewed in this paper. It was found that local bonding between the bolt and the grout can prevent the cone from moving and effectively absorbing dynamic energy. To solve the debonding issue and provide consistent performance of modified cone bolts (MCB), we developed a new patented debonding agent in the form of a plastic sleeve installed over the shaft of the cone bolt. Dynamic and static laboratory testing combined with in situ pull tests confirmed the new system's functionality. Drop tests confirmed that this new debonding agent is much more effective than grease used in the original cone bolt design. In addition, the new cone bolt is designed for $33 \mathrm{~mm}$ boreholes and thus can be used in a onepass rock support system to facilitate rapid drift development in underground mines. The new fully debonded MCB33 cone bolt is characterised by higher dynamic energy absorption capacity, consistent performance, and the ability to withstand repeated impacts from sequential rockburst events.
\end{abstract}

\section{Introduction}

As the depth of mining and underground construction increases, stress induced rock fracturing is inevitable and in some cases the rocks can fail violently, leading to seismic events and rockbursts. A rockburst is defined as damage to an excavation that occurs in a sudden or violent manner and is associated with a seismic event (Kaiser et al., 1996). Many hard rock mines in Canada, China, South Africa, Australia, Sweden, and other countries have experienced rockbursts to various degrees. Rockbursts can cause fatalities and injuries to workers, damage to mine infrastructures and equipments, and substantially increase investment risk.

Monitoring of seismic events in mines is a very useful tool in outlining potentially hazardous ground conditions and assisting mine management in effective re-entry decision. Advanced three-dimensional numerical modelling can identify potentially high stress areas and assist in mine planning and design. However, due to uncertainties in rock mass properties and boundary conditions (e.g. in situ stress), all engineering design, calculations, and seismicity monitoring will have to rely on effective rock support as the final line of defence to ensure underground safety. In addition to maintaining a safe working environment, proper rockburst support also ensures profitability for the mine by protecting investment underground.

Rock support in burst-prone ground differs from conventional rock support where controlling gravity induced rock falls is the main concern. Rock support in burst-prone grounds needs to resist dynamic loading and large rock dilation due to rock failure. Much research has been conducted (e.g. Hedley, 1992; Kaiser et al., 1996; Ortlepp, 1992; and many others) to address the rockburst problem. These studies recommend and provide means for the design of rockburst support as a means to mitigate rockburst damage.

A rock support system is to help the rock support itself (Hoek and Brown, 1980). The role of rock support in underground construction can be classified into three major functions - reinforce, retain, and hold (Kaiser et al., 1996). Under dynamic loading condition, the rock support system must be able to absorb energy to survive the rockburst event. Over the years, various rock support products have been developed and used in practice. Among them, cone bolts stand out as good holding and energy absorbing elements in a rockburst support system. This paper presents a brief review of the development of various types of cone bolts, identifies debonding as a most important issue for the effective performance of cone bolts, and describes a recent development to address the debonding problem. 


\section{$2 \quad$ Need for yielding support in bursting ground}

\subsection{Rock dilation due to rock fracturing}

When a rock fractures, its volume increases significantly. This phenomenon cannot be properly represented in continuum mechanism using the concept of rock dilation angle. Figure 1 shows the results of a numerical simulation using ELFEN (Rockfield Software Ltd, 2003), an FEM/DEM combined code that can properly simulate rock fracturing processes. Because displacement loading boundary is applied, the rock failure process is stable and there is no violent rock ejection and disintegration. When the peak strength is reached, the rock starts to dilate and $8-10 \%$ of volume increase is observed in this case when the vertical straining reaches about $2 \%$. In other words, when a $2 \mathrm{~m}$ thick ring of rocks fail in this fashion with $8-10 \%$ bulking; the maximum wall displacement would be $160-200 \mathrm{~mm}$, which is far beyond the deformation capacity of most standard ground support systems. Of course, the support may affect the bulking behaviour and reduce the bulking to a lower value. However, field measurements suggest that support cannot fully eliminate bulking.

Rock bulking resulting from disintegration of rocks due to violent rock fracturing can lead to even greater volume increase. One typical example of rock bulking is floor heave in underground excavation. In South Africa, complete drift closure due to floor heave has been encountered during severe rockbursts. In Canadian mines, bulking in the floor is commonly observed on the order of 20 to $40 \%$ of the fractured rock zone (if unconfined), typically leading to floor heave of 0.2 to $0.4 \mathrm{~m}$. Consequently, Kaiser et al. (1996) recommend a bulking factor of $30 \pm 5 \%$ to estimate the anticipated floor heave in small to medium sized drifts.

\subsection{Yielding design principle}

When a seismic event occurs, rocks can be subjected to large impact loads. When brittle rock fails, it is always associated with large rock dilation. Under dynamic loading condition, the rock support system must be able to absorb energy, accommodate large deformation, and the overall support system must survive the rockburst event. Standard support systems such as rebar with mesh or shotcrete are not effective in controlling rockburst damage. However, rebars play an important role in reducing bulking in the sections where strains are not excessive.

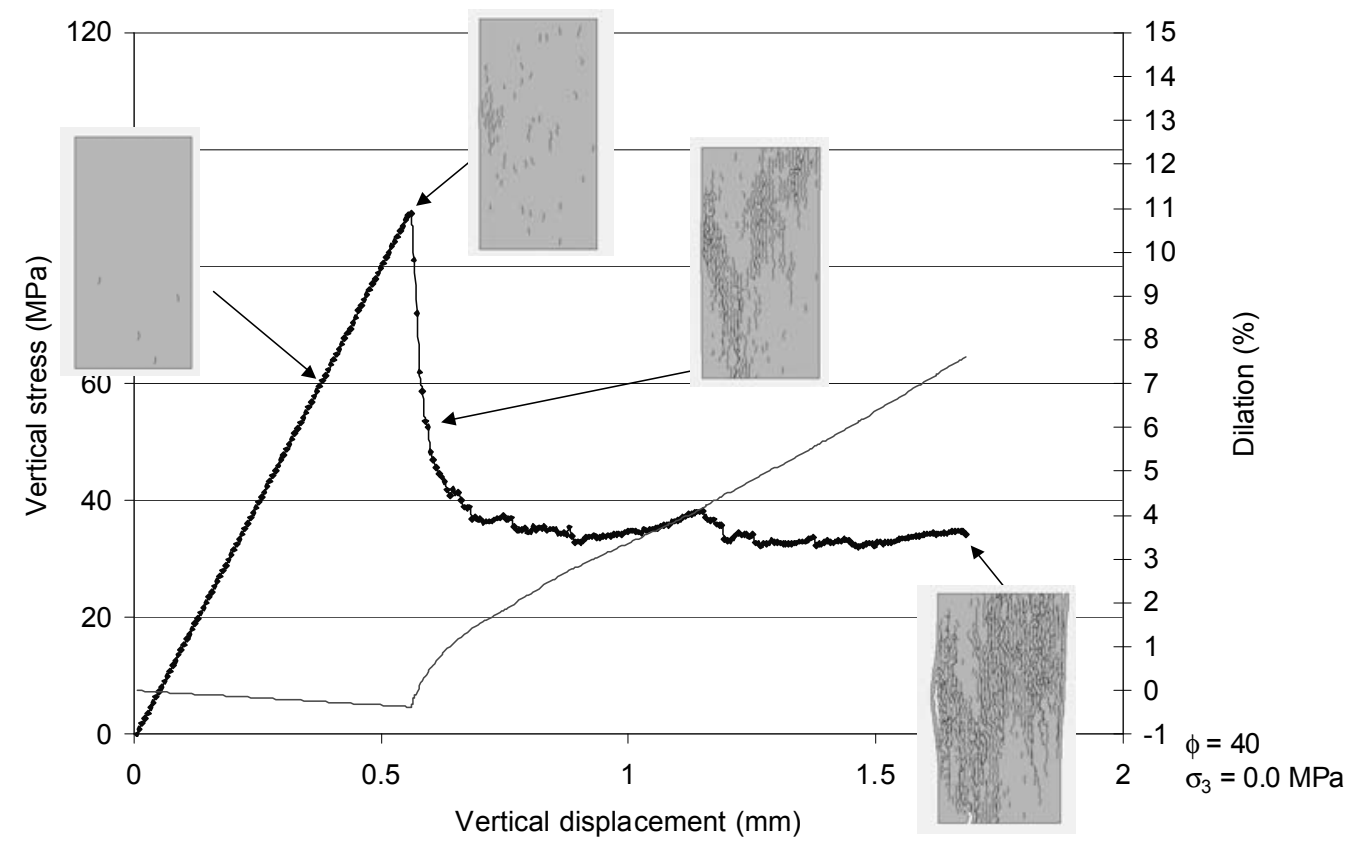

Figure 1 Stress-displacement relation of a rock sample with dilation behaviour (Cai and Kaiser, 2007) 
In addition, when mining at depth, the excavation-induced stresses around underground openings are so high that rock fracturing is inevitable. The stresses are further elevated when the rock is loaded dynamically. In many situations, it is no longer possible to increase the load carrying capacity of the reinforced rock system economically, and the support behaviour must be fundamentally changed to allow for yielding. Jager et al. (1990) showed the dilation pressure resulting from brittle failure in a deep tunnel sidewall exceeded $0.4 \mathrm{MPa}$. When the rock fracturing process is dynamic, it is likely that the pressure will be considerably higher, exceeding the capacity of most practical rock support systems. For reference, the support pressure that can be achieved by a moderately dense pattern of rockbolts is about $0.1 \mathrm{MPa}$. To provide a support pressure of $0.4 \mathrm{MPa}$, very thick cast-in concrete would be required which is clearly not economically practical for most mining applications.

In general, rock pressure decreases with increasing rock deformation. If the rock support system is able to yield in a controlled fashion, we can reach a dynamic equilibrium in the whole deformation process and the system will eventually reach a new static equilibrium.

Hence, the key point is that the rock support system must allow the rock mass to deform, which means that the rock support system must be deformable. A yielding support system should tolerate large tunnel convergence without 'self-destruction' of the system while providing necessary support to ensure safety and maintain serviceability of the tunnel. A yielding rock support system is a system in harmony with its surrounding rocks.

Fortunately, rock bulking can be controlled effectively using appropriate rock support elements, but the rock support system used must be yieldable to accommodate large deformation. Field observation in a few mines confirmed that when yielding support is installed, the wall dilation can be effectively controlled (Figure 2).

Cook and Ortlepp (1968) first suggested the use of yielding rockburst support in the deep gold mines in South Africa. Smooth bar yielding bolt were developed and tested by Ortlepp in 1969. Many dynamic rockbolts have since been developed and the cone bolt is one of a wide spectrum of available tools for burstprone ground. In the following, we briefly review the development of cone bolts and identify an important issue with the existing cone bolts and present a new design which improves the performance of cone bolts.

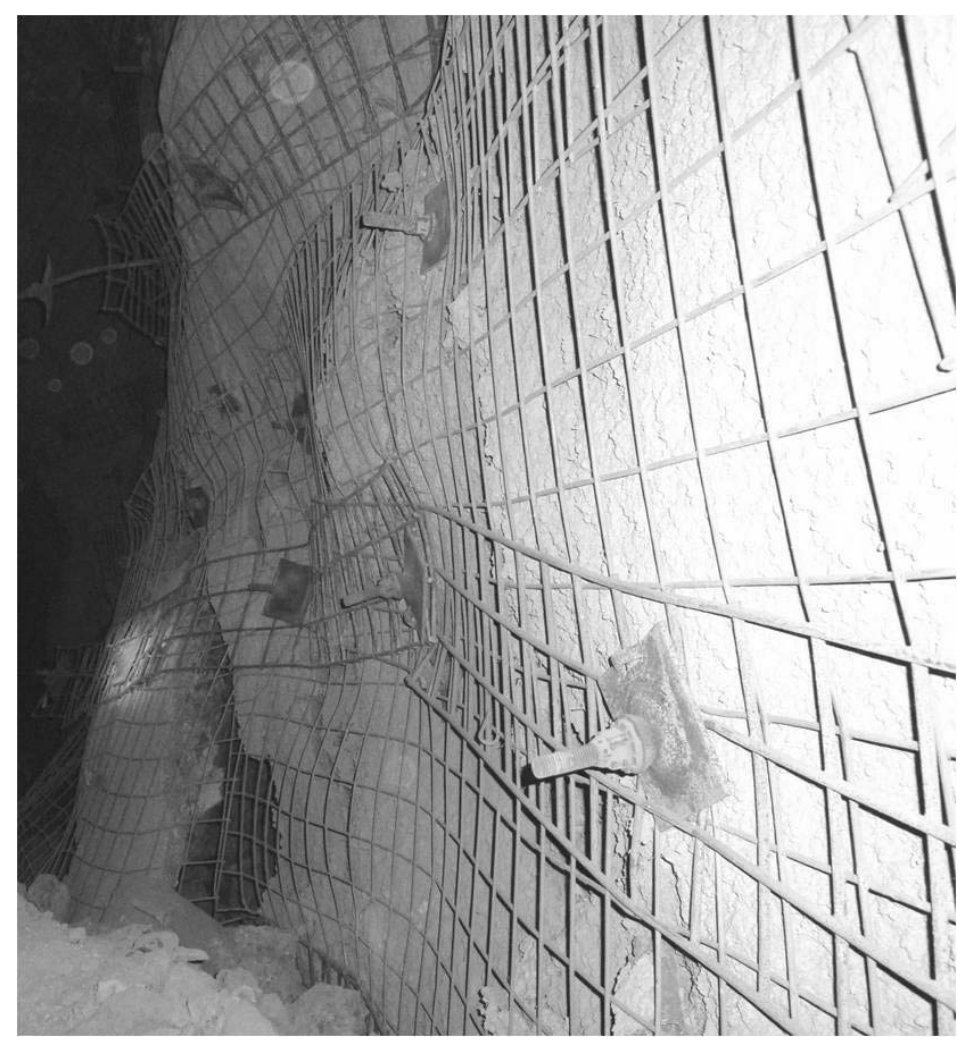

Figure 2 Large wall bulking contained by yielding support 


\section{Historical development of cone bolts}

\subsection{South African cone bolts}

The concept and idea of cone bolt was firstly developed in South Africa. The cone bolts were groutable yielding tendons developed by the Chamber of Mines Research Organization (COMRO) in 1987 (Jager, 1992) for use in cement grouted holes. When subjected to static loading, the cone functions as a wedge-style mechanical anchor similar to standard mechanical rockbolts. However, when subjected to dynamic loading, the cone bolts yielded or plough through the grout, thus absorbing the dynamic energy through controlled deformation.

The initial design of the South Africa $16 \mathrm{~mm}$ diameter cone bolts required that the tendon have a static yield load capacity greater than $100 \mathrm{kN}$, a mean dynamic yield load capacity greater than $50 \mathrm{kN}$ and a maximum deformation capacity of $500 \mathrm{~mm}$. This led to an energy absorption capacity of $25 \mathrm{~kJ}$ (Jager, 1992). Ease of installation was also an important consideration. Because cement grouting of shepherd's crook tendons was generally practiced in South Africa, ease of installation led to the use of cement grout for the cone bolts. To facilitate the bolt's yielding or ploughing through the grout, little or no bonding between the grout and the bolt was permitted. Debonding was therefore achieved by coating the bolt with wax. The wax used was a special saponified wax developed and patented. The wax, which adheres well to steel, has an appropriate melting point and viscosity for ease of applying a thin layer of coating to the bar. One issue related to the use of wax was that its stability was affected in the presence of ammonia. If the wax coated bolts were stored for long periods of time underground in areas contaminated by blasting fumes, the wax could potentially lose its effectiveness.

The resistance of cone bolt to load can be adjusted by carefully dimensioning the conical shape of the anchor. To ensure that the cone penetrates deeply enough into the grout, the cone is flattened on two parallel sides, allowing the maximum cone diameter to be increased while keeping the working area constant (Figure 3). It was found from rapid loading tests $(2 \mathrm{~m} / \mathrm{s}$ loading rate) that the optimum maximum diameter of the cone was 24 to $25 \mathrm{~mm}$ for a $16 \mathrm{~mm}$ diameter bar when embedded in cement grout with a uniaxial compressive strength greater than $20 \mathrm{MPa}$. Domed plate and spherical seat are used to allow better tensile load transfer from the plate to the bolt. Cone bolts were also commercially available in 20 and $22 \mathrm{~mm}$ diameter lengths.

Ortlepp (1994) conducted a quarry site blasting test to demonstrate the effectiveness of South African cone bolts in absorbing kinetic energy. The test arrangement consisted of six identical reinforced-concrete blocks held down against a level concrete surface by the tendons that were to be tested. Each block was secured by five bolts, which were grouted into holes drilled into the granite floor. For valid comparisons of the responses of several different types of elements, the load had to be applied in a reproducible manner. Blast holes were positioned under the block, in between the block and the ground. The concrete blocks take the blasting load and transfer the load to the rockbolts. This test demonstrated vividly the dynamic capacities of rebar, smooth bar, and cone bolt, by examining damage to bolts and measuring the block heave height.

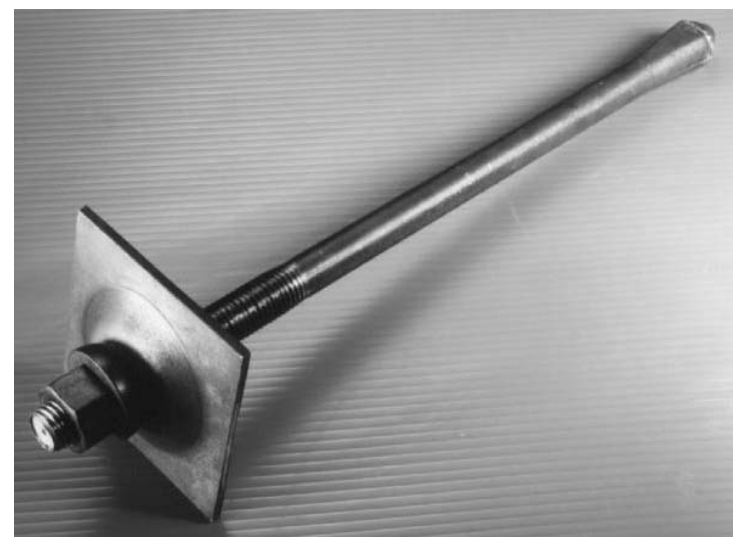

Figure 3 South Africa cone bolts (photo from www.steeledalescs.co.za) 
Figure 4 summarises the test result and it is seen that cone bolts can satisfactorily dissipate dynamic energy. Compared with the calibration tests where no bolts were installed, the maximum heave heights of blocks supported by rebars did not differ much. On the other hand, the movements of the blocks were stopped after 0.33 and $0.5 \mathrm{~m}$ of displacements when 16 and $22 \mathrm{~mm}$ cone bolts were used for low and high explosives, respectively. Smooth bars of $16 \mathrm{~mm}$ length also did a good job to dissipate the kinetic energy.

The superb energy absorption capacity of cone bolts over rebars was clearly shown in Ortlepp's test. Cement grouted cone bolts have been used in a few Australian mines such as Big Bell Mine (Player, 2004). However, cone bolts were reluctantly accepted in South African mines, even in deep-level rockburst prone mines. This was largely due to the high initial cost (Ortlepp, 2007).

South African cone bolts were first tested in Canada in 1994 (Tannant and Buss, 1994) using cement grout and resin (injected with quick-setting resin grout). The cement grouted cone bolt had a maximum displacement of $240 \mathrm{~mm}$ and the load-displacement curve resembles that of a steel stretching curve, indicating that there was little cone movement during pull-out test. In resin grout testing, the cone bolt could not shear through the resin and failed after only about $100 \mathrm{~mm}$ of displacement. To our knowledge, no mine in Canada systematically used the South African cone bolts in its operation. The main reason being that resin injection was not practical for use at the time and cement grouting was time consuming and required a third pass to torque the bolts once the grout was cured.

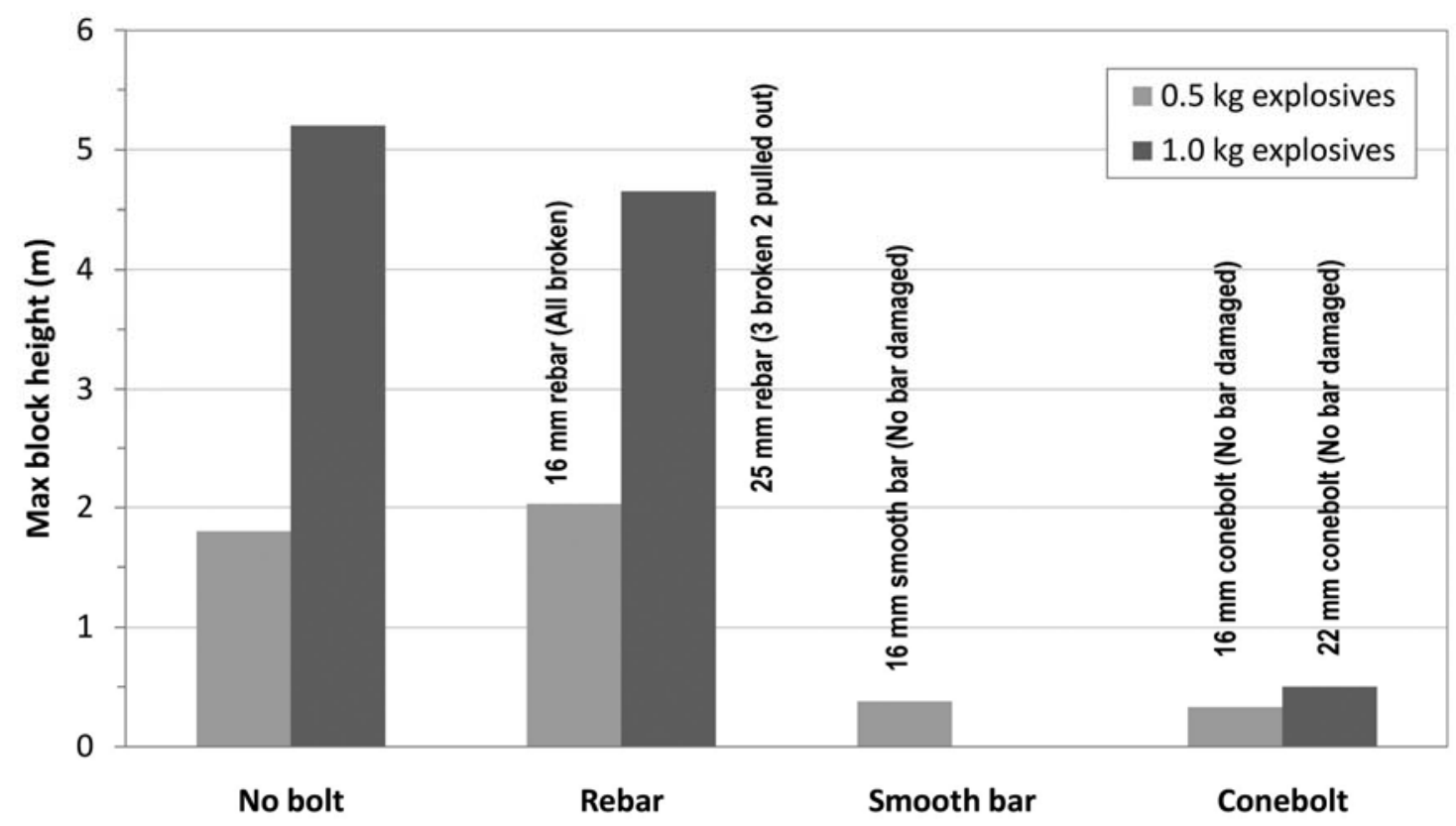

Figure 4 Summary of test result by Ortlepp (1994)

\subsection{Modified cone bolts (MCB)}

The increase in violent ejection failures in 1999/2000 at Brunswick Mine in Canada led to the urgent development of a complete yielding support system (Simser et al., 2002a). The South African cone bolts were modified to accommodate resin-grouting applications in Canada. Noranda Inc. modified the cone bolt head and added a blade for the purpose of resin mixing and the new bolt was called Modified Cone Bolt (MCB). This new tendon can yield in its polyester resin grout matrix. It is a smooth bar threaded at its outer end, with a forged cone and mixing blade at the other end (Figure 5). Grease is used as the debonding agent. Initial dynamic testing was conducted using a one tonne dynamic drop facility designed by MIRARCO (Laurentian University) for the Noranda Technology Centre (the original version of the CANMET drop test facility shown in 10). 


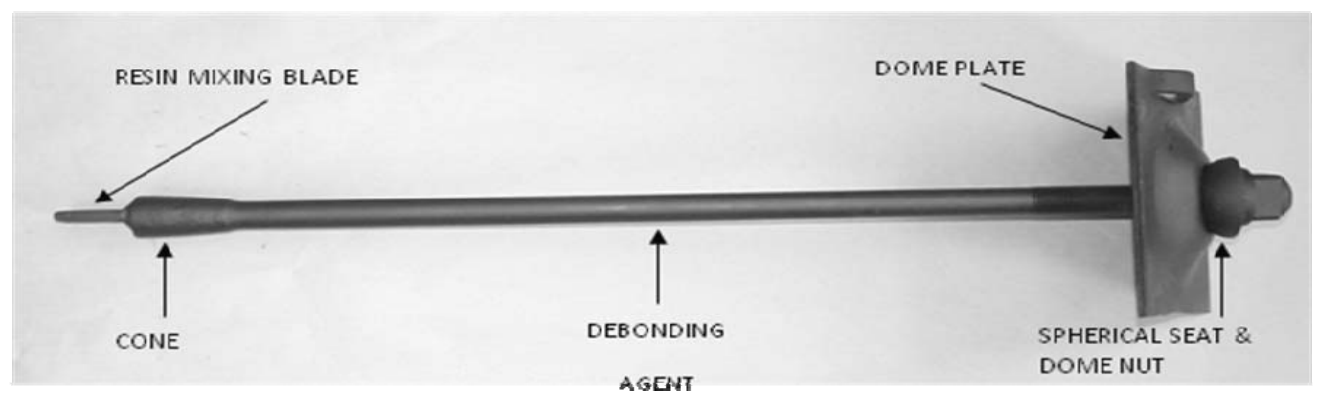

Figure 5 MCB38 cone bolt (photo courtesy: Mansour Mining Inc.)

The initial intent was to proceed with fully-instrumented field trials using simulated rockburst technique, but the urgency of the matter at the mine site dictated that underground installation should be concurrent with further testing. At Brunswick Mine, MCB38 cone bolts (greased) at $1 \mathrm{~m}$ spacing with $150 \times 150 \mathrm{~mm}$, $9.5 \mathrm{~mm}$ thick domed plates, are used with \#0 gauge mesh straps to overlay the diamond mesh $(5 \mathrm{~cm}$ aperture, $5.0 \mathrm{~mm}$ diameter), installed on a second-pass system (Simser et al., 2002a; Simser et al., 2002b).

A close-up view of the rockburst support system installed at Brunswick Mine can be seen in Figure 6 . There was a distinct boundary in one drift that defined stable and unstable grounds in Figure 6a. This boundary was called the 'extreme edge' at the mine site. Beyond the extreme edge, there were only standard rock support systems installed. A series of rockbursts events occurred between October 13 and 17, 2000, severely damaged the ground where standard supports were installed, but the section that was supported by the rockburst support system suffered no damage. On 13 October 2000, a Nuttli magnitude $m_{N}=2.5$ rockburst event caused the collapse of an intersection involving approximately 1,860 tons of material. A small portion of the 326 crosscut immediately east of the intersection had MCB cone bolts installed (a close-up view of the 326 crosscut can be seen in Figure 6b). The right-hand side of the tunnel was supported by $2.3 \mathrm{~m}$ long MCB cone bolts in a $1 \times 1 \mathrm{~m}$ pattern with \#0 gauge mesh straps and chain-link mesh. The left-hand side of the tunnel was supported only by standard support (rebar + shotcrete $+\# 9$ gauge weld mesh). The rockburst support system installation had not been fully completed at the time of the bursts as the chain-link mesh was temporarily suspended with $0.9 \mathrm{~m}$ end anchored rockbolts and the next step of installing MCBs and mesh straps had not be completed. The foreground of the area was supported by rebar and steel fibre reinforced shotcrete. After the rockburst event, it was revealed that the right-hand side of the tunnel suffered no visible damage at all while the rest of the area suffered damage from moderate to severe. The left-hand side showed excessive large bulking.

While this was not intended as a 'field experiment', the observed rockburst damage to different sections clearly showed that a well-designed rockburst support system can effectively limit or eliminate rockburst damage to underground openings.

The excellent performance of the MCB supported tunnel section held the ground so well that many people speculated that the rock might not be hit hard as the rest of the area. However, close onsite examination revealed that the MCBs had fulfilled their role in dissipating dynamic energy as some cone bolts displaced as much as $180 \mathrm{~mm}$ (Simser et al., 2002a). Subsequent use of MCBs based rock support system at the mine site performed exceptionally well.

In 2002, a patent application (US 6,390,735 B1) has been granted for Noranda Inc., regarding the MCB cone bolt. Following the success at Brunswick Mine, MCBs have enjoyed a slow but gradual acceptance by some Canadian mines (e.g. Creighton Mine, Garson Mine, North Mine, Craig Mine, Fraser Mine, Kidd Mine, Red Lake Mine, Laronde Mine) with rockburst problems and have been successfully applied in their operations. 


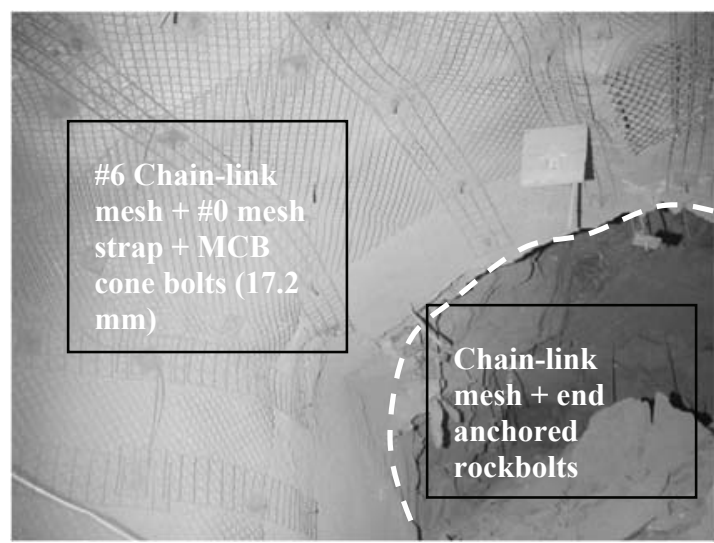

(a)

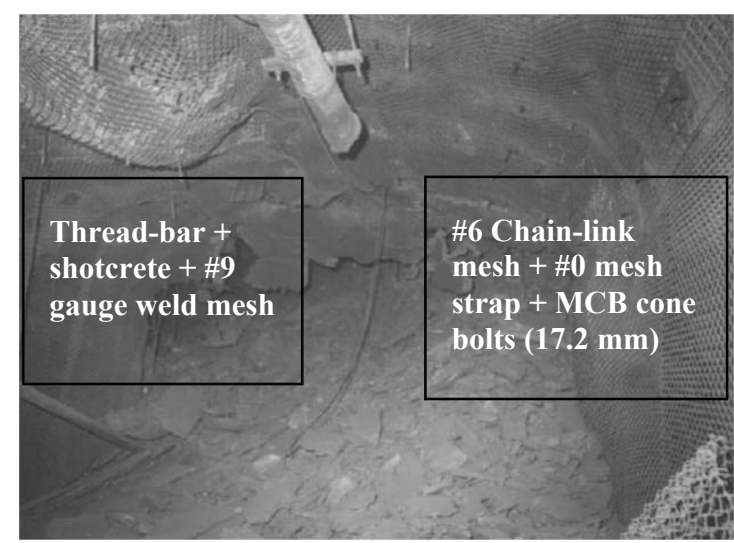

(b)

\section{Figure 6 'Ground truthing' of modified cone bolts at Brunswick Mine (photo courtesy: Brunswick Mine and B. Simser)}

\section{The next generation cone bolt - MCB33}

\subsection{The bonding issue}

The South African (SA) cone bolts have a $0.1 \mathrm{~mm}$ thick saponified wax coating. Approximately 10 months after receiving the SA bolts at Big Bell Mine in Australia, it was noted that some bolts exhibited a substantial deterioration or flaking of the protective wax coating (Player, 2004). The original MCB was greased to reduce the bonding effect between the grout and the bolt. However, it was noted that the spinning action of the bolt to mix the resin stripped off almost all the grease coating, leading to unwanted bond between the bar and the resin.

If wax or grease is not working as intended as a debonding agent, then bonding between the bolt and the grout can reduce the effectiveness of cone bolts. The question is how much bonding exists between the bolt and the grout? This can be found out by static and dynamic tests in laboratory or in the field.

Eight SA cone bolts (22 $\mathrm{mm}$ diameter), four with intact wax coating and four with the wax coating physically removed, were tested at Big Bell Mine to compare the bonding behaviour of bolt and the cement grout $\left(\sigma_{\mathrm{c}} \approx 35 \mathrm{MPa}\right.$ ), with their cones cut off (Player, 2004). The bolt lengths were between 1.0 and $1.5 \mathrm{~m}$. It was seen that for bolts with wax coating physically removed, the peak loads vary between 42 and $92 \mathrm{kN}$ and the residual loads vary between 35 and $70 \mathrm{kN}$, at a displacement of 150 to $200 \mathrm{~mm}$. For the bolts with wax coating, the peak loads vary between 40 and $91 \mathrm{kN}$ and the residual loads vary between 17 and $25 \mathrm{kN}$, at a displacement of 150 to $200 \mathrm{~mm}$ (see Figure 7). The conclusion was that the wax coated smooth bar had on average $25 \%$ and $50 \%$ less peak and residual bond strength per metre of embedment than bolts with wax removed, respectively. In our opinion, these test results suggest that wax coatings are not effective in debonding the cone bolts from the cement grout.

Cai and Champaigne (2009) conducted a series similar pull tests using steel pipes. $1.2 \mathrm{~m}$ long greased MCBs (17.2 $\mathrm{mm}$ diameter) were installed in the pipes using resin. The bolts were fully encapsulated. After the resin was cured, the cone section (about $0.1 \mathrm{~m}$ ) was cut off and the remaining bolt was pull tested until the bolt started to slide in the resin. For comparison purposes, the MCB test results are presented in Figure 7 with the results of Player (2004). In our test, the displacement range was limited to about $35 \mathrm{~mm}$, due to stroke limitation of the ram. It was found that for an embedment length of $0.94 \mathrm{~m}$, the maximum load recorded was $127 \mathrm{kN}$. This load is in fact close to the yield point of the steel bar. Another bar tested with a grease coating had a peak load of $81.6 \mathrm{kN}$. This is also very high, considering the short embedment length of $0.94 \mathrm{~m}$. Similarly to the South African wax coated cone bolts, the test results showed that the grease coating is not effective in debonding the MCBs from the resin grout. 


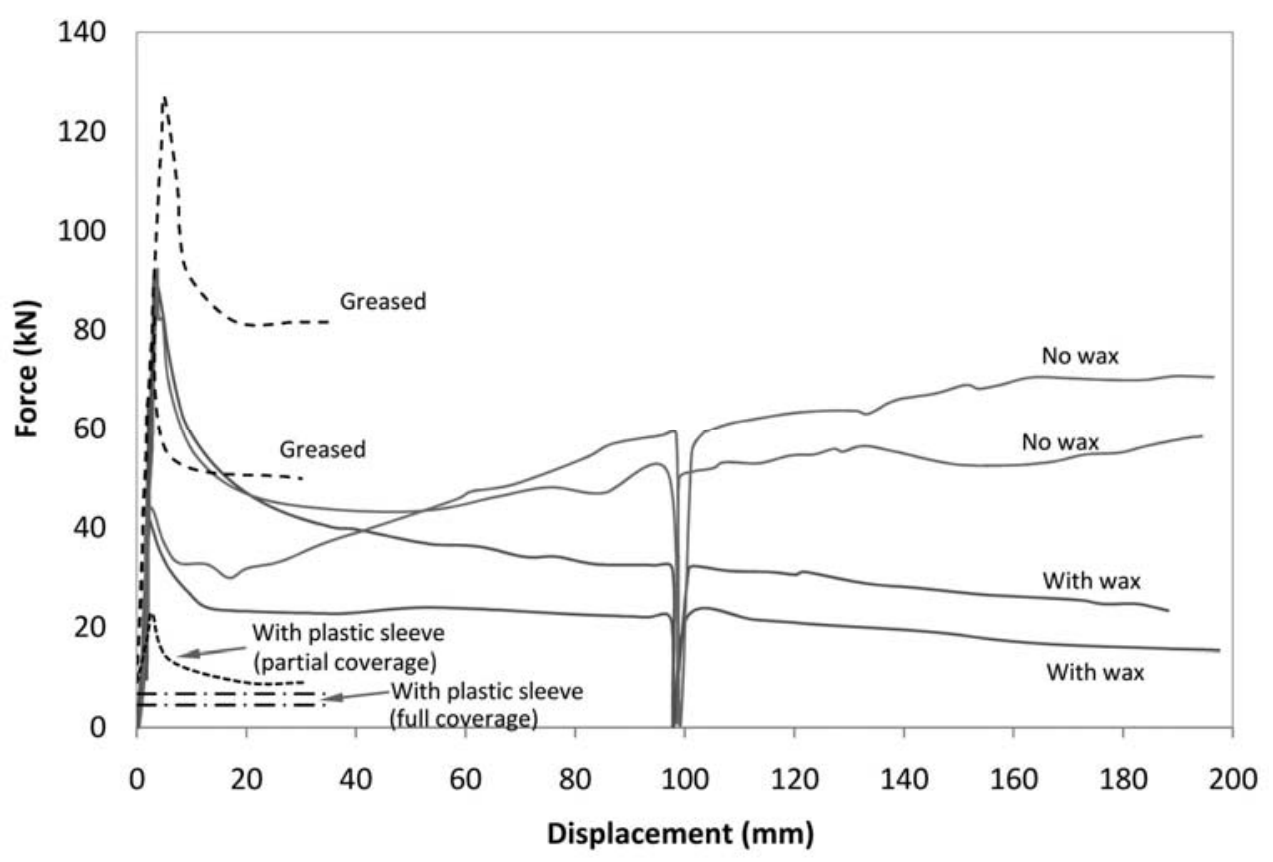

Figure 7 Load-displacement curves of smooth bars with different debonding agents

It can then be concluded that the grease coating was stripped off of the MCBs during the installation process of spinning the bolt through the resin at the manufactures recommended 30-40 revolutions. The final resin matrix quality is important to ensure that the dynamic response of the MCB consistently performs on a repetitive basis and as designed. A number of factors can affect the mixing performance of resin cartridges; insertion rate, rotational speed, bolt to hole annulus, resin viscosity etc. In the case of the MCB33 cone bolt, the borehole diameter was reduced from $38 \mathrm{~mm}$ down to $33 \mathrm{~mm}$, therefore increasing mix-ability considerably.

St-Pierre et al. (2007) conducted dynamic drop tests at CANMET and found that the influence of grease on the bolt behaviour was not obvious. In two of their tests, the cones were cut off and a drop weight of $1016 \mathrm{~kg}$ from $0.5 \mathrm{~m}$ ( $5 \mathrm{~kJ}$ input energy) was used to test the dynamic capability of the smooth bars without cones. The resin embedment length was estimated at $1.2 \mathrm{~m}$. The bar which was greased sustained six drops with a total input energy of $35 \mathrm{~kJ}$ and the non-greased bolt accepted five drops with a total input energy of $30 \mathrm{~kJ}$. Note that $5 \mathrm{~kJ}$ impact energy is large enough to break a fully bonded rebar at the threads. It is interesting to observe from the test result shown in Figure 4 that smooth bars can also have good energy absorption capability. $16 \mathrm{~mm}$ smooth bars performed as well as the $16 \mathrm{~mm}$ cone bolts in the quarry site blasting test.

Mansour Mining conducted dynamic drop tests on MCBs in 2008, with an impact energy of $16 \mathrm{~kJ}$ (drop weight $1,115 \mathrm{~kg}$, drop height $1.5 \mathrm{~m}$ ), to study the effect of grease on the dynamic behaviour of the bolts. Test results showed that greased cone bolts perform only slightly better on average than non-greased bolts $(62.5 \%$ total displacement due to cone movement versus 50\%). In addition, the test results showed that the bolt could withstand $16 \mathrm{~kJ}$ of impact energy three to four times before the bolt breaks. The maximum accumulated steel strain recorded was $10.4 \%$ before the bars broke. Again, this indicated that a large friction component existed between the bolt and resin interface which prevented the cone from ploughing efficiently through resin under repeated loading.

It is obvious from both the static and dynamic testing that both wax and grease are not doing a good job to debond the bolt from the grout. The fact that a smooth bar, whether greased or not, can sustain reasonably high pull out loads or absorb significant amount of impact energy indicates that there is a reasonably large friction force existing between the bolt and the resin. A fully encapsulated smooth bar is, fundamentally, a friction bolt. The frictional force is distributed along the grouted section of the bolt and it becomes obvious that it will limit the cone's ability to plough through the cement or resin grout when subjected to dynamic loading. A new design of the debonding agent is thus required. 


\subsection{The new MCB design with an innovative debonding agent}

It is obvious that an effective debonding agent is required in order to improve the static and dynamic performance of MCBs. No better wax or different grease debonding agent could be identified or developed. As a consequence, Cai and Champaigne (2009) developed a new patented debonding agent in the form of a plastic sleeve installed over the shaft of the cone bolt. The lab test results show that this debonding agent can eliminate the bonding force effectively. As shown in Figure 7, the load for a $0.94 \mathrm{~m}$ section of smooth bar to slide in resin grout is only 4.5 to $6.8 \mathrm{kN}$ if a bar is fully covered by a plastic sleeve. In one test, about $20 \mathrm{~mm}$ of the bar was not covered by the sleeve and it resulted in a peak load of $22.7 \mathrm{kN}$. The residual load of this bar reached to $9 \mathrm{kN}$ at a displacement of $35 \mathrm{~mm}$. The effectiveness of the plastic sleeve as a debonding agent was confirmed.

The new design of the MCB33 cone bolt is shown in Figure 8. The bar diameter is $17.2 \mathrm{~mm}$. The new debonding agent, plastic sleeve, is applied to the whole bar shaft except the cone section and thread section. The sleeve is durable and sleeve damage is unlikely if the bar is handled without abuse. The sleeve is tightly around the bar shaft and there is no sleeve damage or movement during bolt installation. Greased MCBs need to be protected by plastic bags or wood box during transportation to avoid dust sticking to the bolt or the grease being deteriorated. With the new design, the products can be handled similar to rebars or mechanical bolts, greatly simplifies material handling on surface or underground.

There are currently two different cone sizes in use - MCB38 for $38 \mathrm{~mm}$ boreholes and MCB33 for $33 \mathrm{~mm}$ boreholes. Because rebars and rockbolts all use $33 \mathrm{~mm}$ boreholes, it makes much more economical sense to use the MCB33 cone bolts, i.e. one bit and one resin. This eliminates extra bits and resin sizes from inventory, greatly simplifies rock support installation. In addition, it is possible to install all standard and rockburst support systems in one pass, which is desired for rapid drift development. Hence, our recent research and development was focused on MCB33 cone bolts. Laboratory testing combined with in situ pull tests confirmed the new system's functionality. Dynamic drop test at CANMET's testing laboratory confirmed that this new debonding agent is much more effective as a debonding agent over grease used in the original design. Detailed test results are presented in the following sections.

\subsection{Static behaviour of the new MCB33 cone bolt}

Forty-six in situ pull tests were performed at five mines in Canada to prove the new design. A few test results are presented in Figure 9. For comparison, load-displacement curves of a $20 \mathrm{~mm}$ rebar and a $16 \mathrm{~mm}$ South African cone bolt are also shown in the same figure. The cement grouted cone bolt (tested by GRC (Kaiser et al., 1996)) shows similar stiff behaviour as rebar until the load reaches $125 \mathrm{kN}$. After the peak load, there is an initial drop in load followed by an ever increasing load. The response of the MCB33 cone bolt is characterised with a gradual increase of load with deformation and a plateau is reached when the displacement is in the range of 20 to $40 \mathrm{~mm}$. After the plateau, the load continues to increase. The tests were stopped because the displacement reached the stroke limit of the ram. The behaviour of the new MCB33 cone bolts is attributed mostly to the cone resistance in resin without the interference of frictional forces between the bolt and resin. This feature may not be very desirable under slow loading rates, however, under high loading conditions, as will be the case under seismic load, complete debonding of the shaft of the bar from the grout can enhance the cone plough performance and is demonstrated in the dynamic drop tests described below.

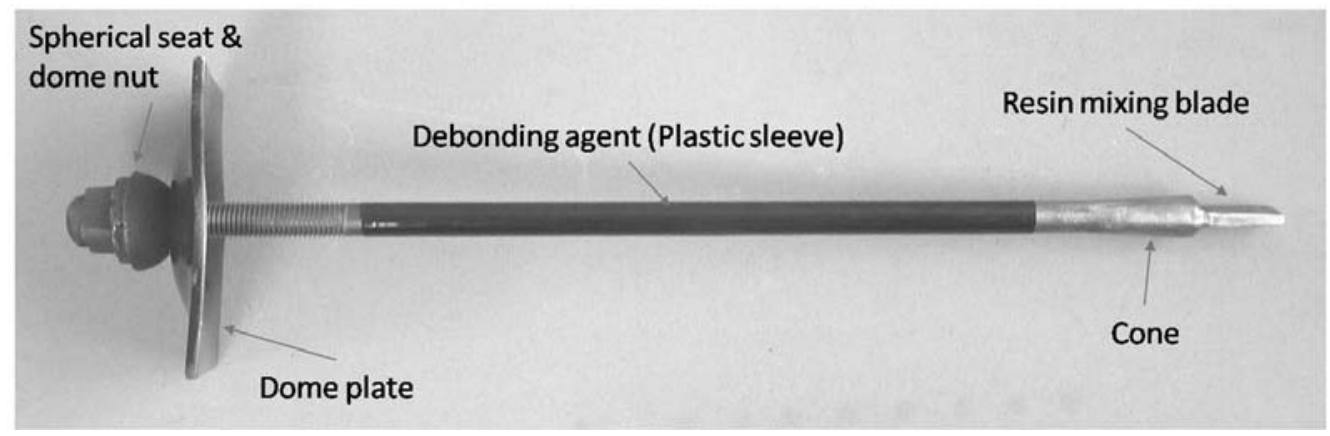

Figure 8 Design of new fully debonded MCB33 cone bolt (patented) 


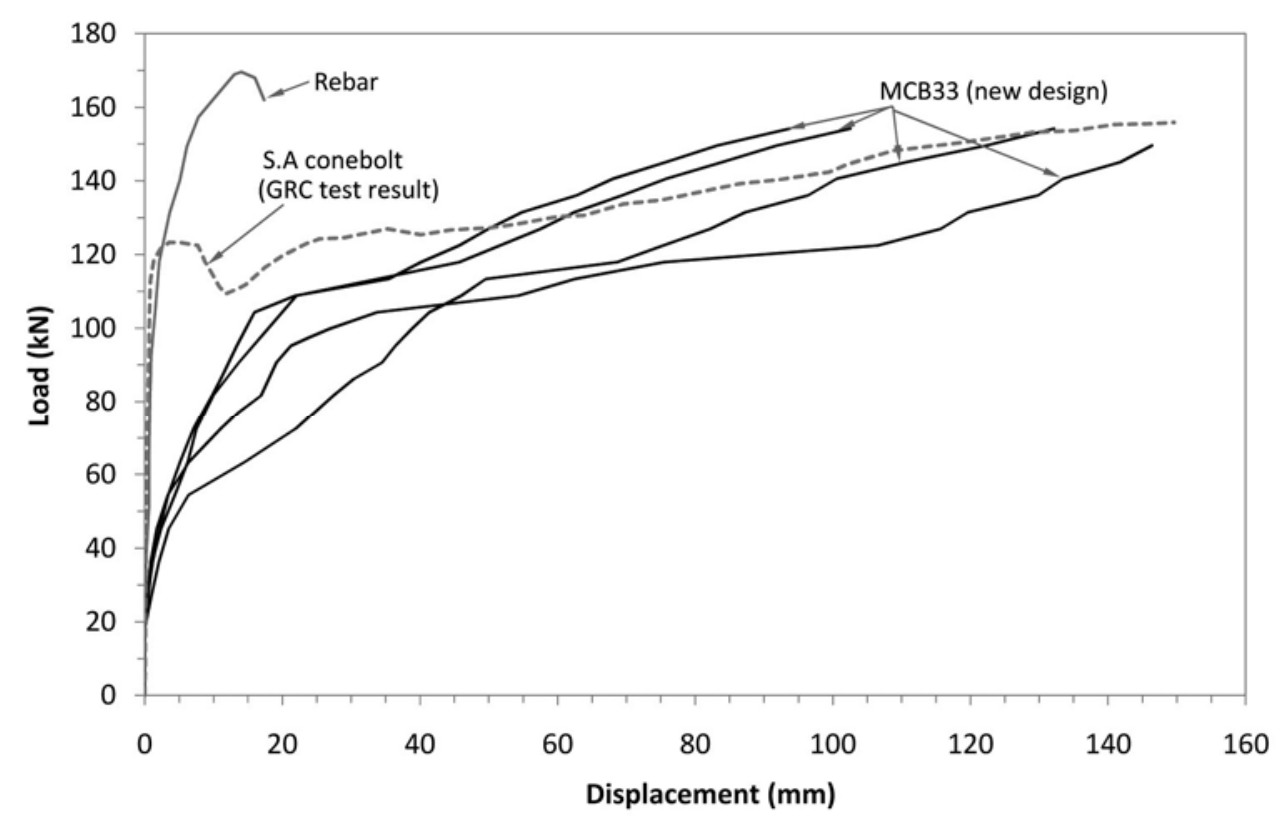

Figure 9 Load-displacement relations of fully debonded MCB33 cone bolts obtained from in situ pull tests

\subsection{Dynamic behaviour of the fully debonded MCB33 cone bolt}

Eight dynamic drop tests were conducted at CANMET in April, 2009 to validate the new design. The drop test facility is shown in Figure 10. This system was originally designed in the late 1990s for Noranda Technology Centre (NTC) by Maloney and Kaiser of GRC (Geomechanics Research Centre, Laurentian University), for a comprehensive laboratory testing program that eventually led to the development of modified cone bolt. The facility was transferred from NTC to CANMET-MMSL's laboratory facilities in Ottawa in 2003. CANMET made a number of improvements to the test facility, including an extension of the drop height, addition of the guide rail, and a computerised measurement system.

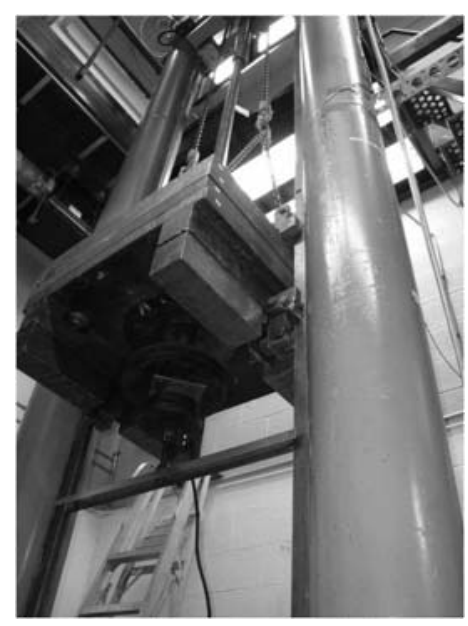

\section{Figure 10 CANMET drop test facility}

Four plastic sleeve debonded cone bolts ( $17.2 \mathrm{~mm}$ diameter) were tested at impact energies of $16 \mathrm{~kJ}$ and the results are compared with the results of previous tests using grease as the debonding agent. Dynamic drop test results showed that on average $99.6 \%$ of the plate displacement was from cone plough on the first drop as compared to $82.9 \%$ in the old design (Figure 11). In the second drop, the cone plough percentages for the new and old designs are 75 and $29.2 \%$, respectively. One new bolt showed an abnormal behaviour in the second drop without cone plough. If this data point is excluded, the cone plough would be $100 \%$ in the 
second drop for the new bolts. In the third drop, the cone plough percentages for the new and old designs are 99.6 and $4.7 \%$, respectively. It is seen that the new design allows the cone to very effectively plough through the resin while the old design relied increasingly on steel stretch to absorb the impact energy of repeated dynamic loading.

It is of interest to explore why greased MCBs performed worse on the second drop. On the second drop one can clearly see more steel stretch and less cone plough in Figure 11. To explain this phenomenon, we need to refer to Figure 7. As explained before, grease could be stripped off during the bolt installation, leaving the shaft of a MCB to come directly in contact with the resin. The smooth bar behaves more or less like the curves of "no wax" shown in Figure 7. Although the curve was obtained in cement grout, we speculate that the response of a naked smooth bar in resin grout will be similar. Load resistance increases as the bars slide in the grout. The first drop test of greased MCB cone bolts resulted in $149 \mathrm{~mm}$ plate displacement (average value). On the second drop, the frictional resistance from the shaft of the bolt is higher than the resistance in the first drop, coupled with the change in cone resistance, the cone plough action became less effective in the second drop (and subsequent drops). As mentioned before, greased MCBs could withstand $16 \mathrm{~kJ}$ of impact energy 3 to 4 times before the bolt broke. This means that the bolts become stiffer after repeated dynamic loading and the cause of this phenomenon can be attributed to the in-effectiveness of grease as a debonding agent.

The implication of this phenomenon is that greased MCBs can become "stiff" after an initial moderate dynamic loading (e.g. $16 \mathrm{~kJ}$ ). Their ability to receive repeated shocks is therefore significantly reduced. For example, a greased bolt (Old MCB33-6) resulted in 54.5\% of steel stretching in the first drop. With this degree of steel stretching, the bolt did not survive the second drop. The new design of the cone bolts eliminates this problem completely. In fact, two new bolts received a third energy input of $16 \mathrm{~kJ}$ and the cone ploughs were 99.4 and $99.7 \%$, respectively.
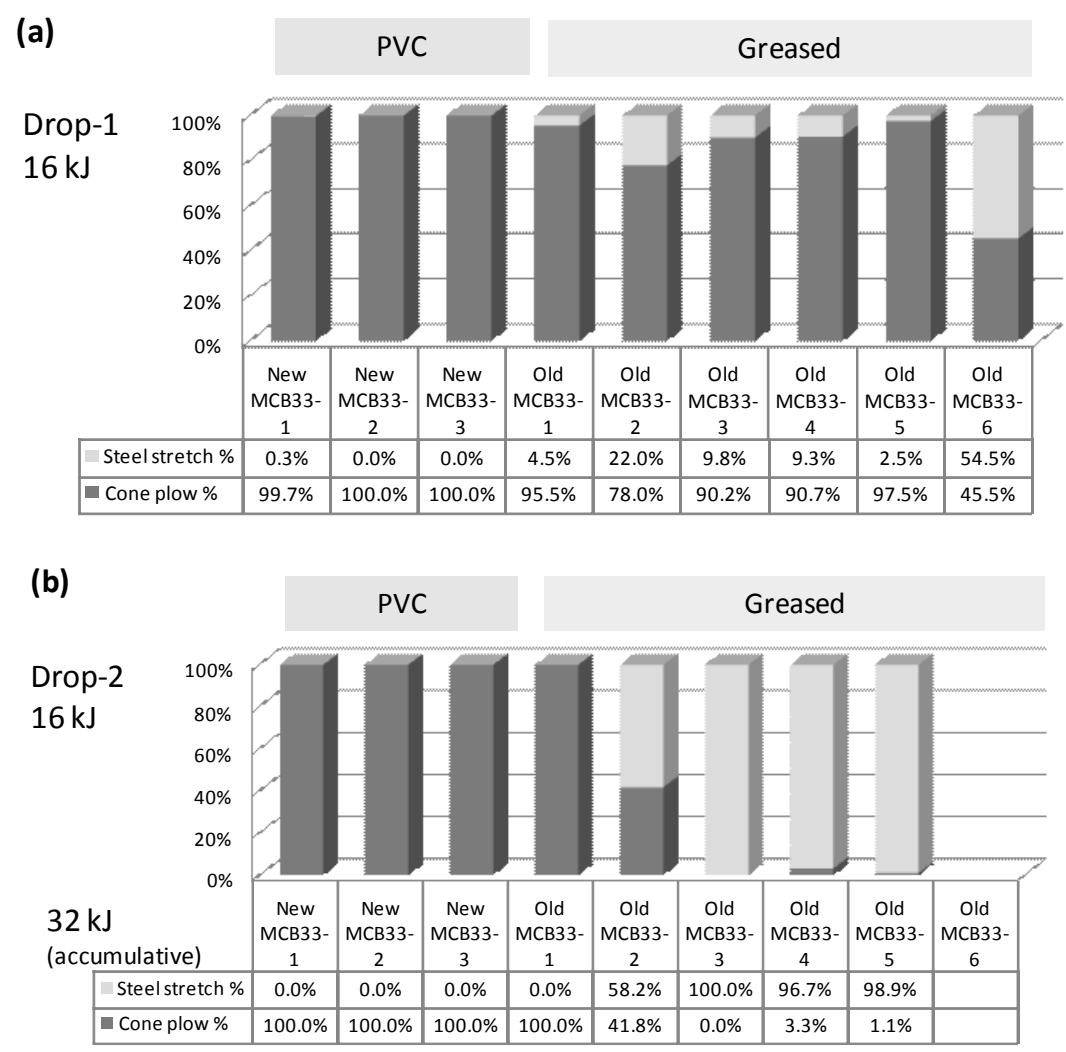

\footnotetext{
Figure 11 Percentage of cone plough and steel stretching for MCB33 cone bolts at $16 \mathrm{~kJ}$ impact energy
} 
Three new MCB33 conebolts with plastic sleeves were tested at $26 \mathrm{~kJ}$ impact energy (1,784 kg weight, $1.5 \mathrm{~m}$ drop height). It resulted in $100 \%$ and $99.9 \%$ cone ploughs in the first and second drops (Figure ). This means that all impact energy was absorbed by cone plough. In our previous drop tests of MCB conebolts, the highest impact energy tested was $22 \mathrm{~kJ}$, with resulting significant steel stretch. Close to perfect cone plough at $26 \mathrm{~kJ}$ was very encouraging and it was decided to use the last available bolt to test at an even higher energy level. The bolt was subjected to a $33 \mathrm{~kJ}$ impact load from a single drop (2,229 kg weight, $1.5 \mathrm{~m}$ drop height) and the bolt survived. Cone plough constituted $76.3 \%$ of the total displacement and steel stretch was $23.7 \%$, which represents only $5.6 \%$ steel strain. This bolt did not survive the second drop at the same energy input level (33 kJ). Bolt MCB33-7 did not fail in the second drop. The plate hit the floor so that displacement measurement could not be correctly conducted.

Figure 13 presents the relationship between bolt displacement and absorbed impact energy. Data other than MCBs are obtained from Player et al. (2009). It is seen that when toe anchored thread bars fail at the thread and absorb very little energy $(<2 \mathrm{~kJ})$. The fully bonded threadbars are tested using load transfer by separating the bolt in the middle of the installed pipe. The debonded threadbars have about $1.6 \mathrm{~m}$ debonded section which allow the steel to stretch. All data points are from the first drop loading. Four threadbars failed but there were no cone bolts failures on the first drop. A very good linear correlation between steel strain and energy absorption can be seen from the threadbar data. It is observed that the cement grouted South Africa cone bolts and at least two of our old MCB cone bolts follow the trend line, indicating that the dominant energy absorption mechanism of those cone bolts had been steel stretch with very little cone plough. On the other hand, the new MCB design allows the cone to plough much more efficiently, and their capacities to absorb dynamic energy are thus substantially increased.

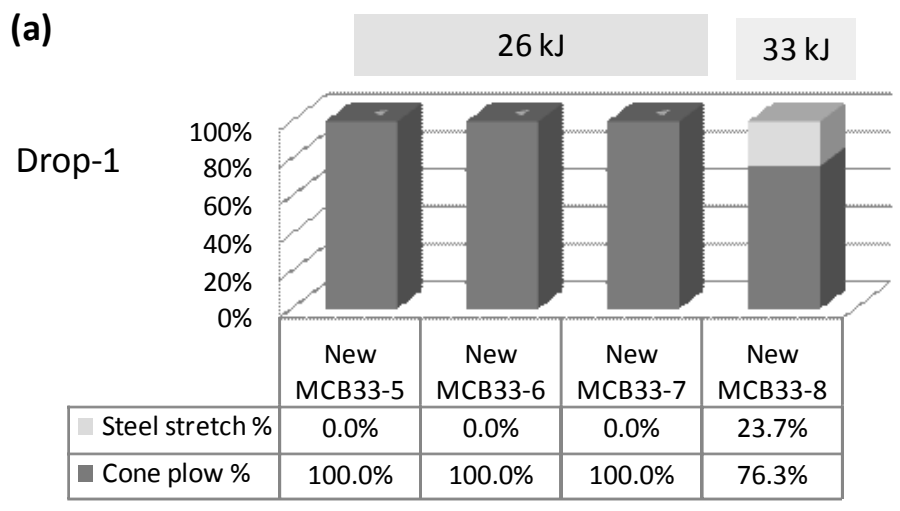

(b)

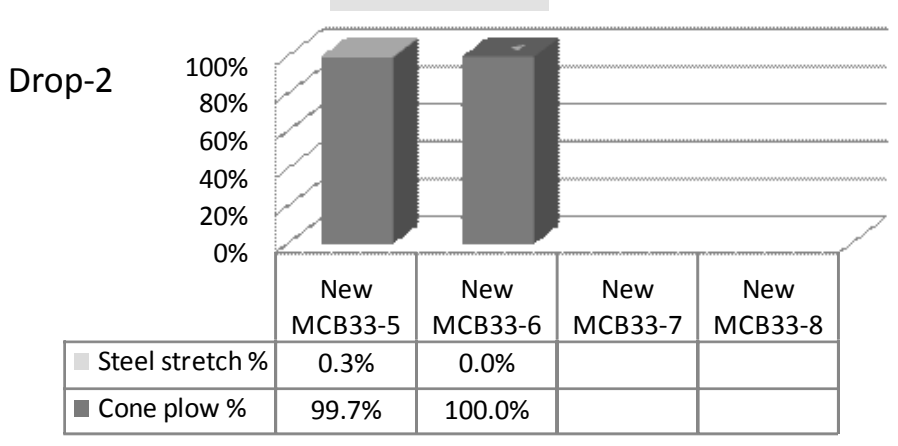

Figure 12 Percentage of cone plough and steel stretching of MCB33 cone bolts at $26 \mathrm{~kJ}$ and $33 \mathrm{~kJ}$ impact energy 


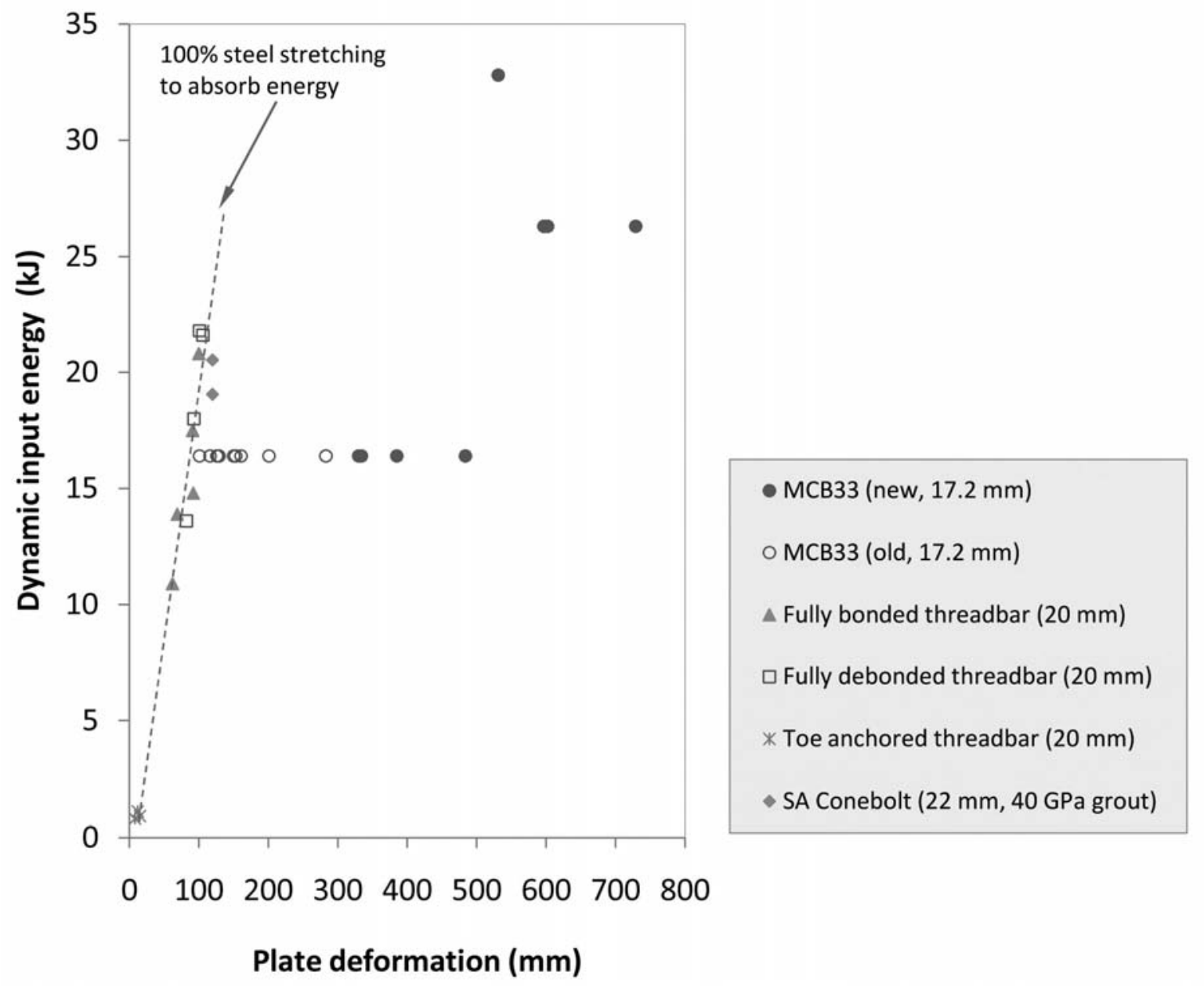

Figure 13 Energy dissipation of MCB33 and other bolts versus plate deformation. 'New' and 'Old' stand for plastic sleeve and grease debonded cone bolts, respectively

\section{Conclusion}

The use of yielding support is a key component when designing a rockburst support system. Modified cone bolt based rockburst support systems have been proven to be very effective to mitigate/limit rockburst damage.

As Ortlepp (1992) pointed out in a lecture, "For most components, some kind of yielding device is conceptually simple but much small-scale but innovative work is still required to determine the most practical." Recent development at Mansour Mining Inc. to fully debond the MCBs from the resin grout is such a small but innovative work. The new design has greatly improved the dynamic capability of the cone bolt and it is expected that it will perform even better in severe and repeated rockburst situations. In addition, the conical head of MCB has been modified to make the bolt suitable for use in $33 \mathrm{~mm}$ diameter boreholes. Hence, the new fully debonded MCB33 cone bolts can be used in a one-pass rock support system to facilitate rapid drift development in underground mines.

Ortlepp (1992) also pictured that the "ideal tendon" would retain the inherent stiffness provided by the high modulus of steel up to a load value close to its elastic limit and then would yield, maintaining a constant resistance until the movement of the rock had been arrested. The new MCB cone bolt may not be perfect but is one step closer to the "ideal tendon." 


\section{Acknowledgements}

The authors wish to acknowledge Xstrata Nickel, Xstrata Copper, Kirkland Lake Gold, Vale, and Goldcorp for their support during the field test of the development of the new MCB33 cone bolt. The authors also wish to thank Mike Hill of Mansour Mining for assisting in situ testing and CANMET for executing the dynamic drop test. Permission to publish the dynamic test results from Mansour Mining Inc. is gratefully acknowledged.

\section{References}

Cai, M. and Champaigne, D. (2009) The art of rock support in burst-prone ground. Keynote Lecture, in Proceedings RaSiM 7: Controlling Seismic Hazard and Sustainable Development of Deep Mines, Tang, C. A. (editors), pp. 33-46.

Cai, M. and Kaiser, P.K. (2007) The role of rock support in highly stressed ground support design and selection rationale, Phase-I Supplemental report submitted to Rio Tinto on proposed semi-empirical design approach. Geomechanics Research Centre, Laurentian University, Sudbury, Ontario, 36 p.

Cook, N.G.W. and Ortlepp, W.D. (1968) A yielding rockbolt. Chamber of Mines of South Africa Research Organization Bulletin (14).

Hedley, D.G.F. (1992) Rockburst Handbook for Ontario Hardrock Mines. CANMET Special Report SP92-1E, 305 p.

Hoek, E. and Brown, E.T. (1980) Underground excavation in rock. Institution of Mining and Metallurgy, London, $527 \mathrm{p}$.

Jager, A., Wojno, L.N. and Henderson, N.B. (1990) New developments in the design and support of tunnels under high stress, in Proceedings Technical Challenges in Deep-level Mining, SAIMM Congress, Johannesburg, Vol. 1, pp. 1155-1171.

Jager, A.J. (1992) Two new support units for the control of rockburst damage. In: Rock Support in Mining and Underground Construction, P.K. Kaiser and D.R. McCreath (editors), pp. 621-631.

Kaiser, P.K., Tannant, D.D., and McCreath, D.R. (1996) Canadian Rockburst Support Handbook. Geomechanics Research Centre, Laurentian University, Sudbury, Ontario, 314 p.

Ortlepp, W.D. (1992) The design of support for the containment of rockburst damage in tunnels an engineering approach. In: Rock Support in Mining and Underground Construction, P.K. Kaiser and D.R. McCreath (editors), pp. 593-609.

Ortlepp, W.D. (1994) Grouted rock-studs as rockburst support: A simple design approach and an effective test procedure. J. South Afr. Inst. Min. Metall., 94: pp. 47-53.

Ortlepp, W.D. (2007) Dynamic capacity in cable anchors and rockbolts, in Proceedings 1st International Symposium on Block and Sublevel Caving, pp. 405-420.

Player, J.R. (2004) Field performance of cone bolts at Big Bell mine, in Proceedings Ground Support in Mining and Underground Construction, E. Villaescusa and Y. Potvin (editors), pp. 289-298.

Player, J.R., Thompson, A.G. and Villasescusa, E. (2009) Dynamic testing of threadbar used for rock reinforcement, in Proceedings ROCKENG09: 3rd CANADA-US Rock Mechanics Symposium, M. Diederichs and G. Grasselli (editors), Toronto, Paper 4030.

Rockfield Software Ltd (2003) ELFEN, 3.7. <http://www.rockfield.co.uk/>.

Simser, B., Andrieus, P. and Gaudreau, D. (2002a) Rockburst support at Noranda's Brunswick Mine, Bathurst, New Brunswick, in Proceedings NARMS 2002, R. Hammah, W. Bawden, J. Curran and M. Telesnicki (editors), University of Toronto, Canada, Vol. 1: pp. 805-813.

Simser, B., Joughin, W.C. and Ortlepp, W.D. (2002b) The performance of Brunswick Mine's rockburst support system during a severe seismic episode. J. South Afr. Inst. Min. Metall., pp. 217-223.

St-Pierre, L., Hassani, F.P., Radziszewski, P.H. and Ouellet, J. (2007) Testing and analyzing the dynamic response of rock support elements, in Proceedings 4th Int. Symp. on High-performance mine production, Aachen, Germany, pp. 353-368.

Tannant, D.D. and Buss, B.W. (1994) Yielding rockbolt anchors for high convergence or rockburst conditions, in Proceedings 47th Canadian Geotechnical Conference, Halifax. 